\title{
Relating anomalous large-scale atmospheric circulation patterns to temperature and precipitation anomalies in the East Asian monsoon region
}

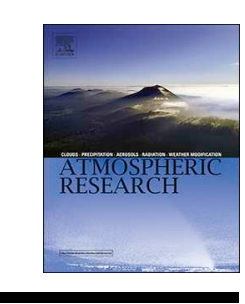

\author{
Ye Yang ${ }^{\mathrm{a}, \mathrm{b}}$, Meng Gao ${ }^{\mathrm{a}, *}$, Naru Xie ${ }^{\mathrm{a}, \mathrm{b}}$, Zhiqiang Gao ${ }^{\mathrm{a}}$ \\ ${ }^{\text {a }}$ Key Laboratory of Coastal Environmental Processes and Ecological Remediation, Yantai Institute of Coastal Zone Research, CAS, Yantai 264003, China \\ ${ }^{\mathrm{b}}$ University of Chinese Academy of Sciences, Beijing 100049, China
}

\section{A R T I C L E I N F O}

\section{Keywords:}

Atmospheric circulation patterns

Self-organizing map

Temperature and precipitation anomalies

East Asian Monsoon

\begin{abstract}
A B S T R A C T
The anomalous large-scale atmospheric circulation patterns concerned with surface air temperature and precipitation anomalies within East Asian Monsoon region for winter and summer months from 1979 to 2017 are analyzed by employing the self-organizing map (SOM) neural network. The asymmetric $3 \times 4$ SOM neural network is firstly constructed with the geopotential height anomalies at 500-hPa level as the only input variable. Then 12 characteristic anomalous large-scale atmospheric circulation patterns (nodes) are identified. The composites of temperature and precipitation anomalies as well as vertical wind anomalies at 500-hPa level assigned to each node are generated and visualized. The spatial distributions of anomalous geopotential height (anticyclones or cyclones) are highly consistent with that of surface air temperature anomalies in both winter and summer. Most precipitation extremes in winter are attributed to the joint effect of the horizontal and vertical atmospheric motions, while strong air convection is prone to inducing extreme precipitation events in summer. Based on the SOM classification, the differences of atmospheric circulations, temperature and precipitation anomalies have also been partly identified in strong and weak phases of East Asia Monsoon.
\end{abstract}

\section{Introduction}

Temperature and precipitation extremes, regarded as the most devastating weather events, usually cause serious impacts on ecosystems, economy and human health (IPCC, 2007). The intensities and frequencies of climate extremes have been significantly increasing over the past few decades triggering widespread attentions (Katz and Brown, 1992; Peterson et al., 2002; You et al., 2011). Relevant studies suggested that the variations of temperature extremes would be stronger at regional and local scales due to global warming, while the changing pattern of precipitation extremes was uneven and incoherent in different regions (Zhai et al., 1999; Alexander et al., 2006; Haylock et al., 2006; Klein Tank et al., 2006; Brown et al., 2008; Li et al., 2012; Ohba et al., 2015). Thus, an effective adaptation to future climate variations deserves extensive research on the relationships between large-scale atmospheric circulations and temperature and precipitation extremes (Robeson, 2002; Wen et al., 2015; Gao et al., 2016; Agel et al., 2017; Ford and Schoof, 2017; Loikith et al., 2017).

The synoptic-scale circulations, involved with key atmospheric ingredients such as geopotential height of a certain pressure level and sealevel pressure, are generally considered as the main factors contributing to the climate extremes (Grotjahn and Lee, 2016). The large-scale atmospheric circulation patterns (LSACPs) are usually related to regional environmental variables in studying the climate extremes (Yarnal, 1993; Sheridan and Lee, 2012). The most vital core is the identification of main characteristics of LSACPs and subtle variabilities. There are a few of methods available that could be used to discern the LSACPs associated with climate extremes at local or regional scales. Hart et al. (2006) classified the surface and upper air meteorological conditions from October to March over a 10-year period in Sydney into the LSACPs using principal component analysis (PCA), and explored the influence of atmospheric circulation on ozone pollution. Riddle et al. (2013) applied the K-means clustering (KMC) approach to characterize the anomalous LSACPs in winter over the North American region. Lau and Nath (2014) conducted the EOF analysis on anticyclonic circulation anomalies to construct the LSACPs relating to heat extremes in North America and Europe, respectively. The self-organizing map (SOM) is an unsupervised neural network approach that could project high-dimensional input data on to a relatively low dimensional space (Kohonen, 1995). The SOM method has been prevalently employed in meteorology and oceanography (Cassano et al., 2006; Cassano et al., 2007; Ohba et al., 2015; Agel et al., 2017; Loikith et al., 2017). According to Liu and Weiberg (2011) and Hewitson and Crane (2002), the SOM method has significant advantages of continuity and accuracy than conventional

\footnotetext{
* Corresponding author.

E-mail address: mgao@yic.ac.cn (M. Gao).
} 

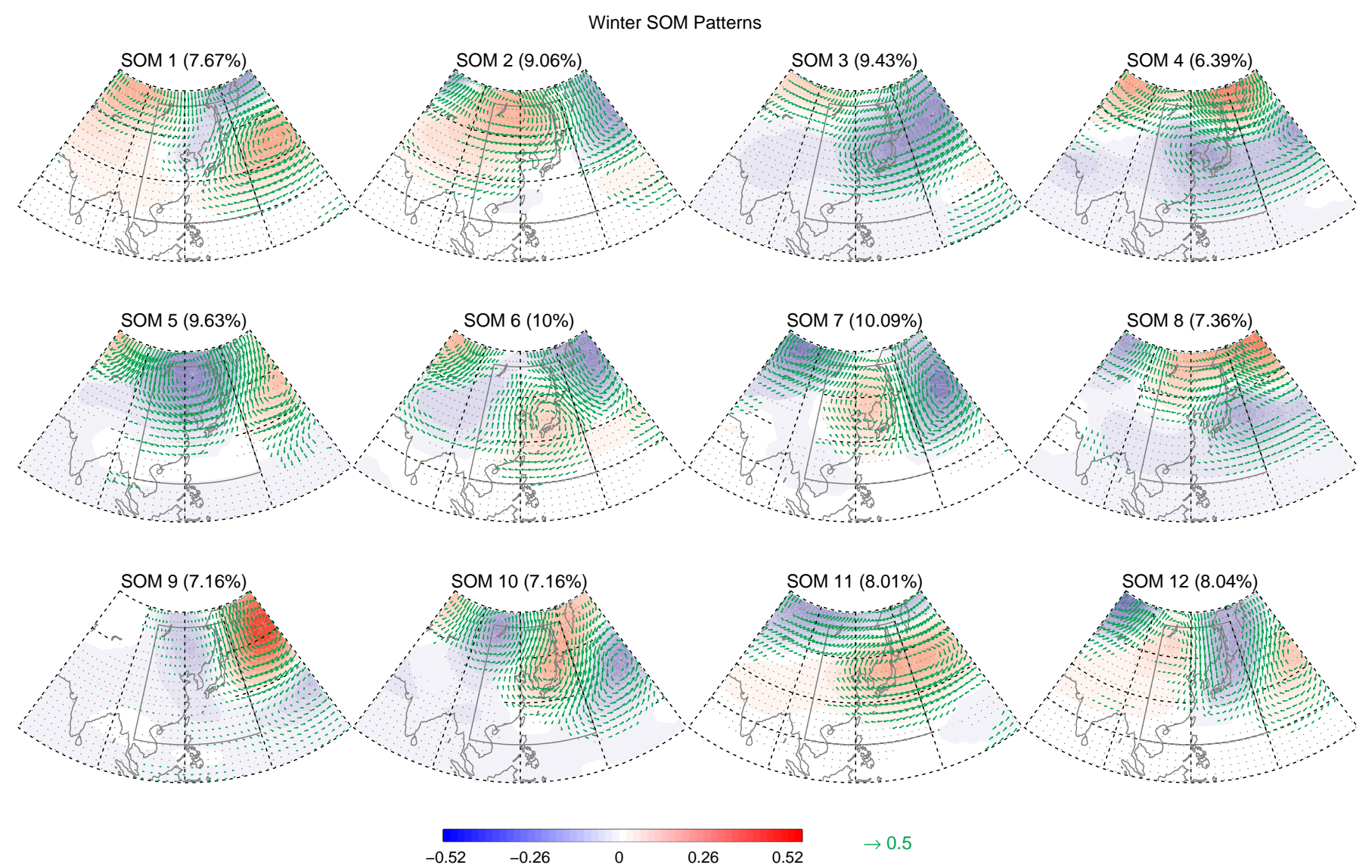

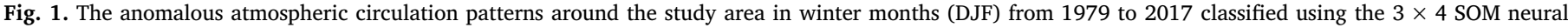

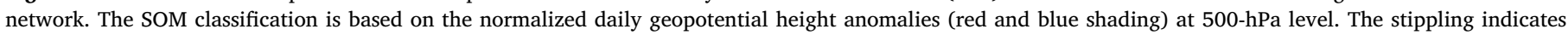

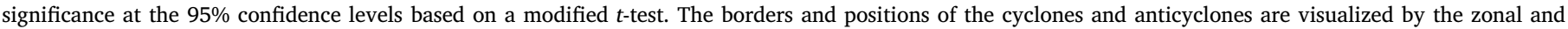

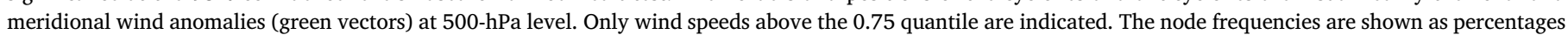
in the parentheses. (For interpretation of the references to colour in this figure legend, the reader is referred to the web version of this article.)

feature extraction methods such as PCA or EOF. Loikith et al. (2017) applied the SOM method to characterize LSACPs and related them to temperature and precipitation extremes over the Northwestern United States. Moreover, the influence of ENSO on anomalous atmospheric circulation patterns and climate anomalies were also visualized based on the above SOM classification. Agel et al. (2017) combined the KMC and SOM methods to generate the LSACPs of dynamic tropopause pressure anomalies relating to extreme precipitation in the US northeast. Gao et al. (2019) applied the SOM method to reveal the relationships between anomalous LSACPs and temperature anomalies over China and quantified the relative contribution of atmospheric circulation changes to climate extreme changes.

Monsoon systems represent the dominant variation in the climate, and about a quarter of the globe experiences a monsoon climate (Trenberth et al., 2000). The East Asian Monsoon is a typical regional monsoon system driven by the temperature differences between the East Asian continent and the Pacific Ocean (Ding and Chan, 2005). It affects approximately one-third of the global population, and can be divided into 2 distinct climate subsystems, a warm and wet summer monsoon (EASM) and a cold and dry winter monsoon (EAWM). The EASM southeasterlies are closely correlated with the intraseasonal variations of the rainband within East Asia, for example, Meiyu season in the Yangze River valley, Baiu season in Southwest Japan and Changma season in South Korea. The EAWM is characterized by strong northwesterlies over North, Northeast China, Korea, and Japan and strong northeasterlies along the coast of East Asia, which is the main reason of cold extremes in winter and sand dust-storms in spring over the northern East Asian (Huang et al., 2003). It is worthy to study the relationships between anomalous atmospheric circulations and climate extremes in East Asia to better understand the association of LSACPs and climate extremes within the East Asian monsoon system. Wang and Ho (2002) defined the EASM domain as the region of $20^{\circ} \mathrm{N}-45^{\circ} \mathrm{N}$ and $110^{\circ} \mathrm{E}-140^{\circ} \mathrm{E}$, except for the South China Sea (Ding and Chan, 2005). In our study, we choose the domain bounded in $15^{\circ} \mathrm{N}-55^{\circ} \mathrm{N}$ and $100^{\circ} \mathrm{E}$ $150^{\circ} \mathrm{E}$ as the study area, which is denoted as the East Asian monsoon region (EAMR).

The primary objective of our study is to explore the relationship between anomalous LSACPs and temperature and precipitation anomalies in winter and summer months within the East Asian monsoon region by applying SOM method. In addition, the LSACPs and climate extremes under strong or weak EASM and EAWM conditions are also analyzed. This paper is organized as follows. The description of data is presented in Section 2, and the SOM methodology is presented in Section 3. Results of SOM-based composite analysis are shown in Sections 4. Finally, discussions and conclusions are given in Section 5 and Section 6, respectively.

\section{Data}

Three climate ingredients, geopotential height (Z500), horizontal (including zonal and meridional wind) and vertical winds at $500-\mathrm{hPa}$ level (1979-2017) involved in this study are derived from the ECMWF interim reanalysis dataset within the region $0^{\circ}-60^{\circ} \mathrm{N}, 60^{\circ}-180^{\circ} \mathrm{E}$ (Dee et al., 2011, data accessed April 2018). Specifically, Z500 is used because it depicts mid-tropospheric circulation very well and presents a significant correlation with surface variables (Tolika et al., 2007; 

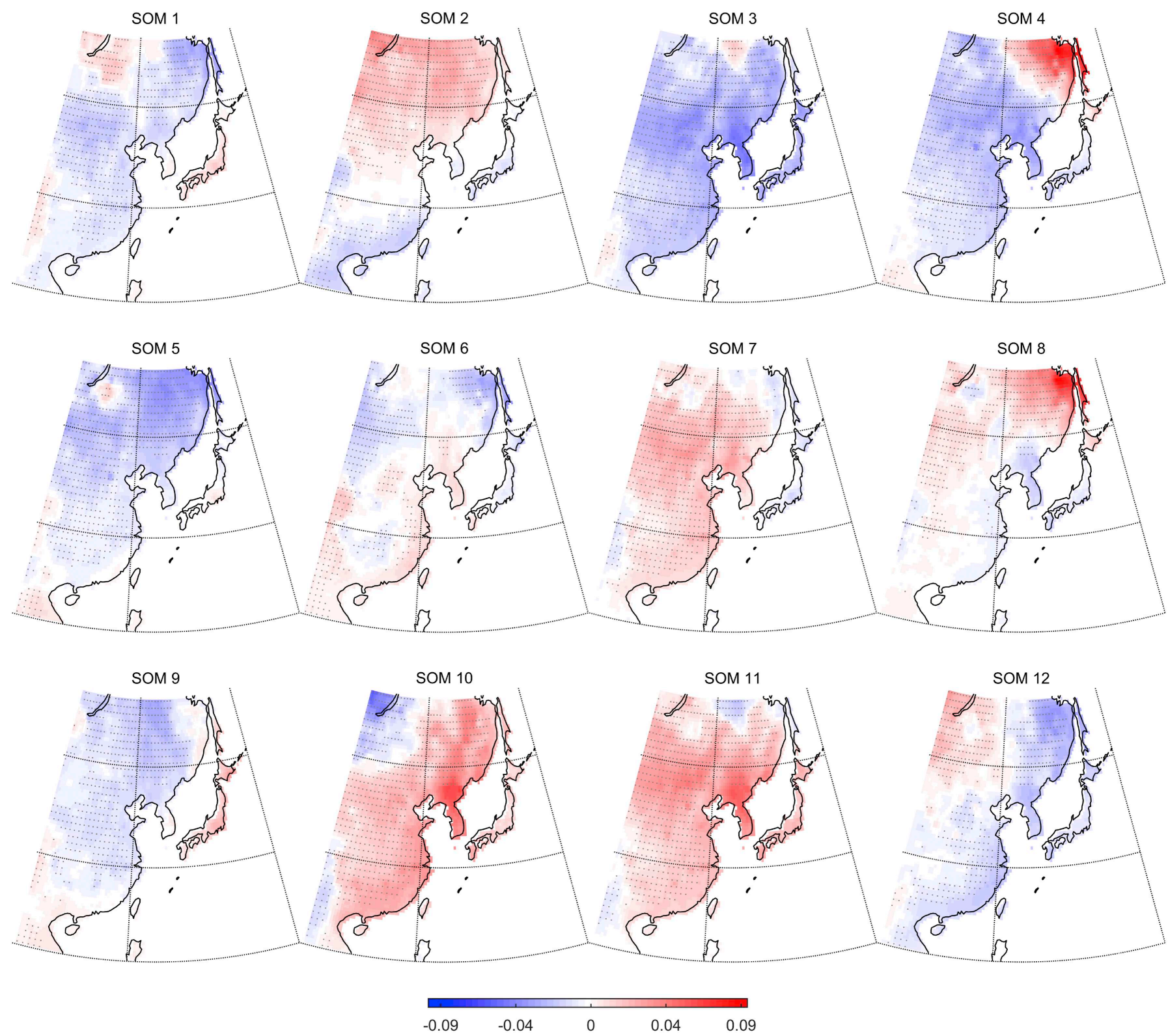

Fig. 2. Composites of daily minimum surface air temperature (Tmin) anomalies in winter months (DJF) from 1979 to 2017.

Horton et al., 2015; Mioduszewski et al., 2016). The anomaly fields of all atmospheric variables are obtained by the deseasonalization process. For instance, Z500 is firstly deseasonalized and normalized to generate the daily anomaly fields. Next, the daily anomaly fields of Z500 are further weighted by the square root of the cosine of latitude to account for area differences across the grid points (Ohba et al., 2015; Gao et al., 2019). The horizontal winds are used to indicate the location and range of cyclones and anticyclones on the composite maps. Vertical velocity of wind at $500-\mathrm{hPa}$ level, which is tied to the moisture convection in the atmosphere, is applied to explain the precipitation anomalies under different LSACPs (Higgins et al., 1997; Wu et al., 2009). In this study, the winter months are specifically December, January and February (DJF), while the summer months are June, July, and August (JJA).

The daily maximum (Tmax) and minimum (Tmin) surface air temperature and daily total precipitation data on a $0.5^{\circ} \times 0.5^{\circ}$ grid within the study area EAMR $\left(15^{\circ} \mathrm{N}-55^{\circ} \mathrm{N}, 100^{\circ} \mathrm{E}-150^{\circ} \mathrm{E}\right)$ are provided by the National Oceanic and Atmospheric Administration Climate Prediction Center in U.S (available at https://www.esrl.noaa.gov/psd/data/ gridded/data.cpc.globaltemp.html and https://www.esrl.noaa.gov/ psd/data/gridded/data.cpc.globalprecip.html). The daily mean climatology for temperature and precipitation are firstly calculated and smoothed. Then, the smoothed mean climatology is subtracted by daily values generating the surface air temperature anomalies. Especially, the smoothed mean precipitation is divided by the daily precipitation, and the ratio represents the precipitation anomaly.

The East Asian Winter Monsoon index (EAWMI in winter months) and Western North Pacific Monsoon index (WNPMI in summer months) concerned with the East Asian monsoon, are adopted in this study to define the intensity of EAWM and EASM, respectively. In this study, the EAWMI is defined as an index based on the normalized area-averaged sea level pressure differences between the Siberia $\left(40^{\circ} \mathrm{N}-60^{\circ} \mathrm{N}, 70^{\circ} \mathrm{E}\right.$ $\left.120^{\circ} \mathrm{E}\right)$, the North Pacific $\left(30^{\circ} \mathrm{N}-50^{\circ} \mathrm{N}, 140^{\circ} \mathrm{E}-170^{\circ} \mathrm{W}\right)$, and the Maritime Continent $\left(20^{\circ} \mathrm{S}-10^{\circ} \mathrm{N}, 110^{\circ} \mathrm{E}-160^{\circ} \mathrm{E}\right)$, which is capable of reflecting the intensity and nature of the EAWM (Wang and Chen, 2014). The specific formula is as follows:

$E A W M I=\left(2 \times \operatorname{SLP}_{S}-\operatorname{SLP}_{N P}-\mathrm{SLP}_{M C}\right) / 2$

where $\mathrm{SLP}_{S}, \mathrm{SLP}_{N P}$, and $\mathrm{SLP}_{M C}$ represent the normalized area-averaged 

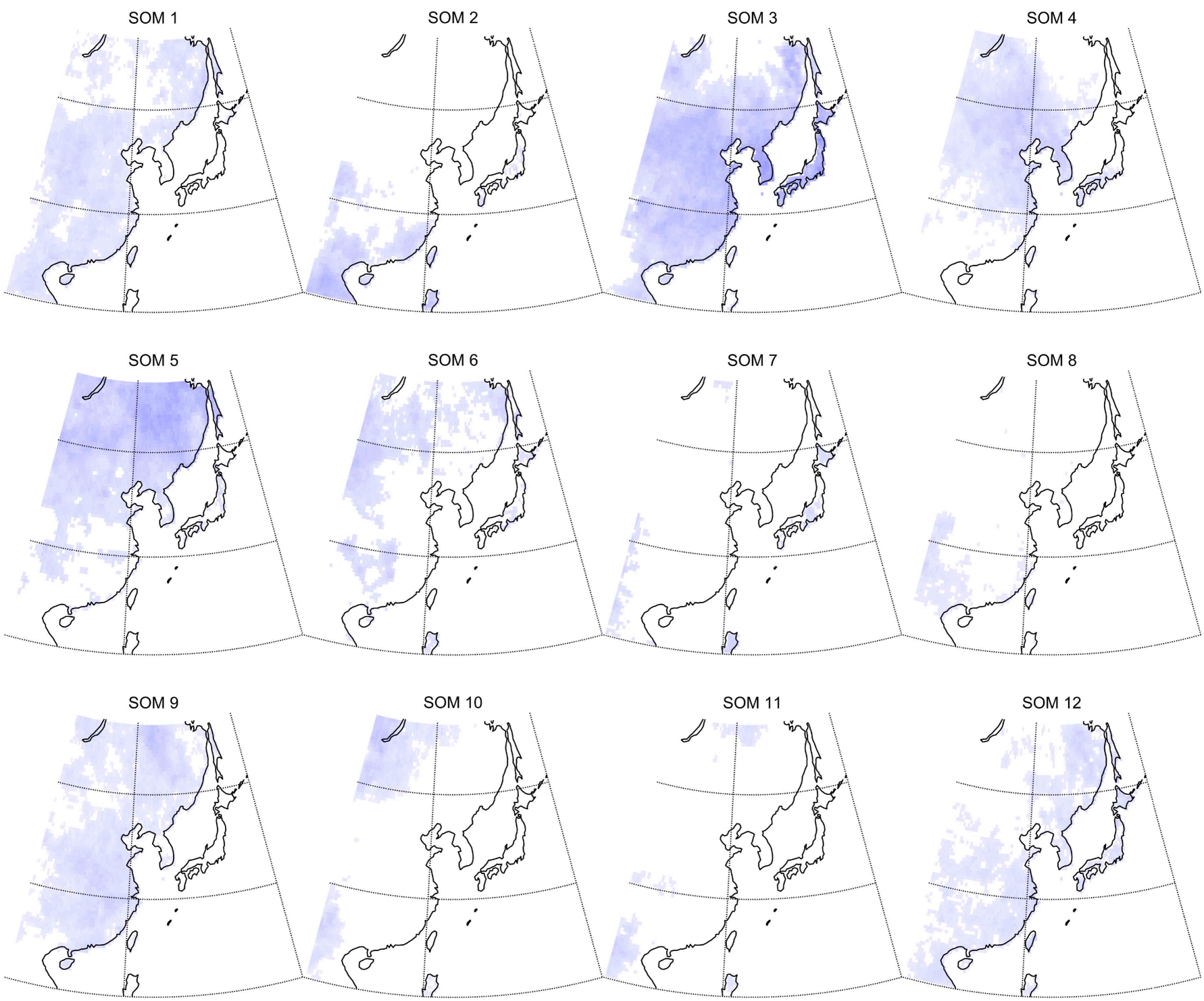

$20 \quad 40 \quad 60 \quad 80$

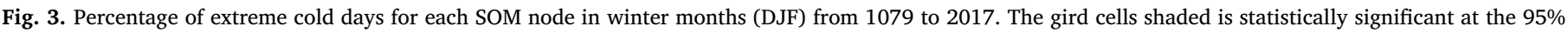
level based on the Monte Carlo simulations.

sea level pressure within the Siberia, the North Pacific and the Maritime Continent. As for the WNPMI, the index, obtained by calculating the difference of $850-\mathrm{hPa}$ zonal winds between the southern region in South China Sea $\left(5^{\circ} \mathrm{N}-15^{\circ} \mathrm{N}, 100^{\circ} \mathrm{E}-130^{\circ} \mathrm{E}\right)$ and the northern region across Southeast China and West Pacific $\left(20^{\circ} \mathrm{N}-30^{\circ} \mathrm{N}, 110^{\circ} \mathrm{E}-140^{\circ} \mathrm{E}\right)$, describes precisely the variations of Asian summer monsoon with feature like multiple time scale (Wang et al., 2001). The specific formula is as follows:

$W N P M I=\mathrm{U}^{2} 50_{s}-\mathrm{U} 850_{N}$

where U850 and $\mathrm{U} 850_{N}$ represent the $850-\mathrm{hPa}$ zonal winds on the southern region in South China Sea and the southeastern coast of China. In this study, we define EAWMI + / EAWMI- as strong/weak winter monsoon and WNPMI + / WNPMI- as the strong/weak summer monsoon.

\section{Methodology}

The SOM method is adapted to study the relationship between LSACPs and climate anomalies or extremes within the EAMR. The SOM has been considered as an effective method to identify local or regional meteorological patterns (Ding and Chan, 2005). It uses unsupervised classification to perform nonlinear mapping of high-dimensional data sets onto regularly arranged two-dimensional arrays referred to as SOMs (Kohonen, 1995). Each of the elements in SOM array is denoted as a node (or neuron). The process involves in all of the input data, so that there is no priori assumption about the distribution of the data for SOM methodology (Hewitson and Crane, 2002). Each piece of input data is distributed into winning node, which is the most similar node based on the minimum Euclidean distance in class space. Then both winning node and neighborhood nodes are updated. The process ensures the similar input fields to assemble together and guarantee the output results to be continuum. After thousands of iterations, the twodimensional SOM array is established finally, where vicinal patterns resemble to each other and far apart those have relatively different characteristics (Agel et al., 2017).

The number of nodes is user-defined and only determined by experimental tests. If the map size is too small, the diversity of highly generalized circulation patterns could not effectively captured; if it is 

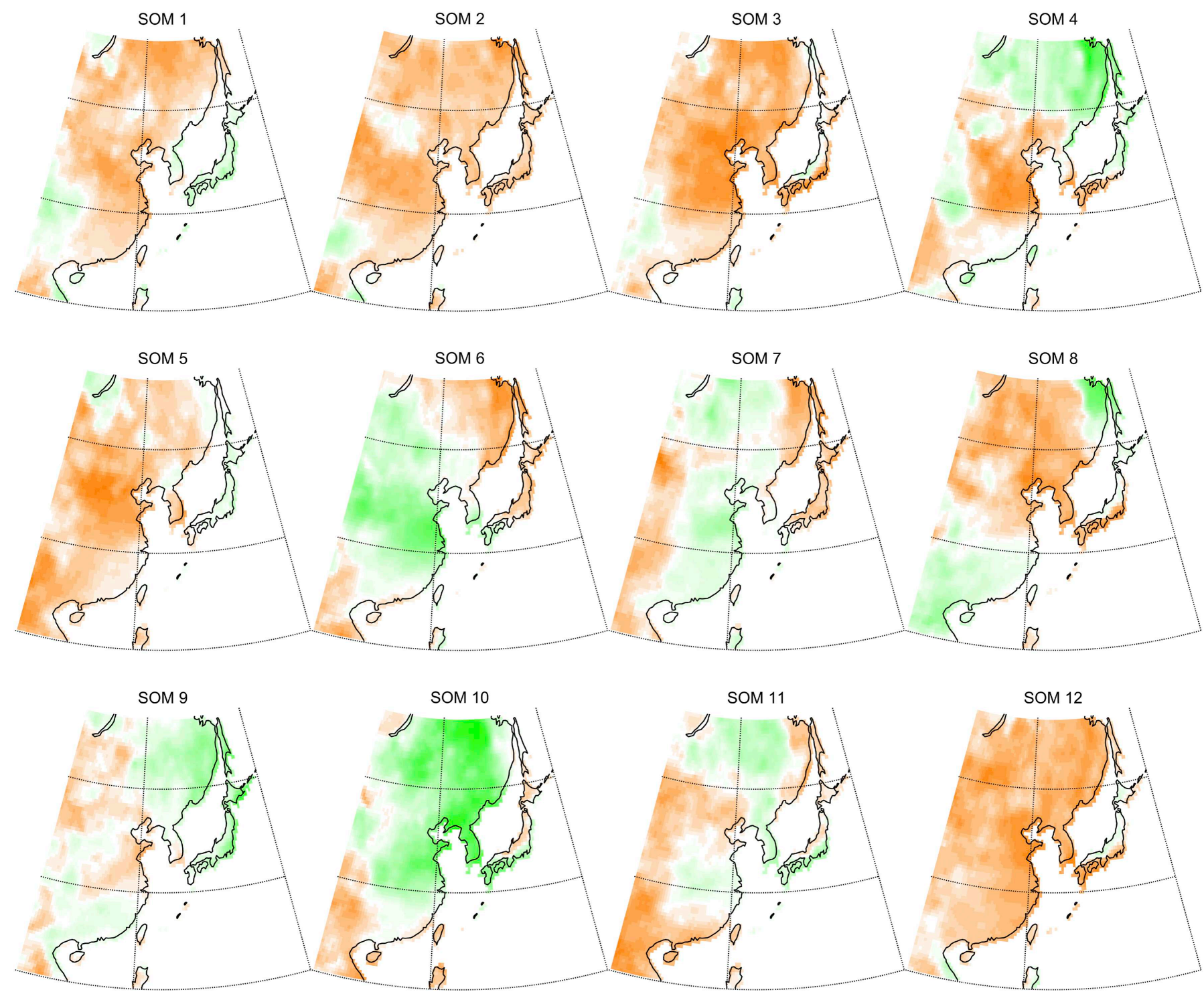

0

1

3

Fig. 4. Composites of daily precipitation anomalies in winter months (DJF). The definition of precipitation anomalies is shown in Data section.

too big, adjacent patterns will be too similar and visualization is unwieldy (Agel et al., 2017; Loikith et al., 2017). In this study, we choose a $3 \times 4$ SOM as Loikith et al. (2017). This $3 \times 4$ SOM is capable to precisely distinguish the critical variability of LSACPs, and the outcome has the brilliant physical interpretation. Other map size has also been tested and the results are not qualitatively changed.

The relationships between the LSACPs and climate anomalies (or extremes) could also been presented in the composite maps of climate anomalies (or extremes) corresponding to each LSACP (Liu and Weiberg, 2011). The statistical significance of all climate anomalies in the composite maps are tested using the modified $t$-test method presented in Brown and Hall (1999). The climate extremes are defined as the coldest (warmest or heaviest) $5 \%$ of the daily Tmin (Tmax or precipitation) anomalies distribution (Loikith et al., 2017). The statistical significance of the percentage of climate extreme concurrent with each SOM node is determined by a Monte Carlo approach (Loikith et al., 2017). The composite maps of vertical wind velocity anomalies corresponding to each SOM are also constructed to investigate the influence of air convection on precipitation anomalies.
To illustrate the influence of EAWM and EASM on LSACPs and climate anomalies within EAMR, the node frequencies in 150 winter (summer) days with highest/lowest EAWMI (WNPMI) values are shown as heat maps, respectively. The statistical significance of differences in node frequency between the strong and weak phases is calculated in a manner similar to Cassano et al. (2007). Under the null hypothesis condition that the frequency difference corresponding to each node between the two phases is zero, the statistical test is conducted as below:

$\frac{p_{1}-p_{2}}{\sqrt{\frac{p_{1}\left(1-p_{1}\right)}{n_{1}}+\frac{p_{2}\left(1-p_{2}\right)}{n_{2}}}}$

where $\frac{p_{1}\left(1-p_{1}\right)}{n_{1}}$ and $\frac{p_{2}\left(1-p_{2}\right)}{n_{2}}$ are variances of two independent, random, binomial processes, $p_{1}$ and $p_{2}$ are the expected proportions of frequency over the strong and weak EAWM (WNPSM) days, $n_{1}$ is the number of samples in highest-index winter (summer) days, and $n_{2}$ is the number of samples in lowest-index winter (summer) days. If the test statistic exceeds 1.96 , we reject the null hypothesis at the $95 \%$ confidence level 

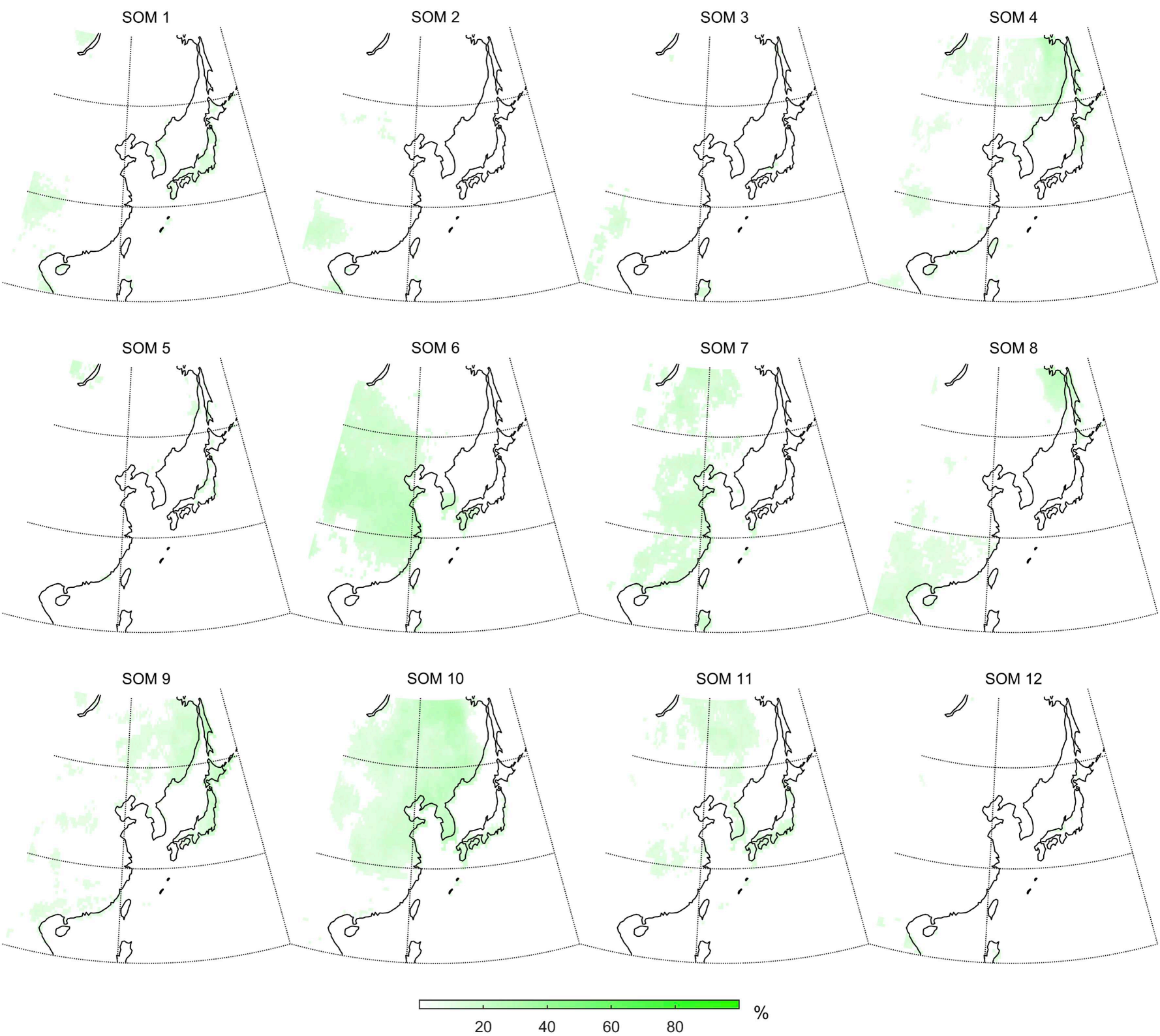

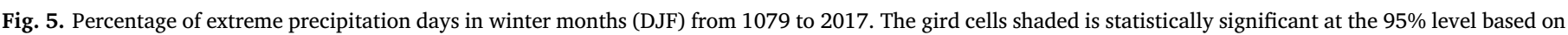
the Monte Carlo simulations.

and consider the frequency difference between the two phases to be significant. This statistical test does not account for the effects of serial correlation in the atmospheric circulation fields, so that it is likely to overestimate the degrees of freedom. Analogously, we also divide the number of samples of the two datasets by 5 resulting in fewer degrees of freedom and therefore a test statistic of greater magnitude and raising the threshold to achieve statistical significance (Mioduszewski et al., 2016; Gao et al., 2019).

\section{Results}

\subsection{Anomalous LSACPs and climate extremes}

1) Winter months

The $3 \times 4$ SOM node patterns for winter months are shown in Fig. 1 , and each node corresponds to one anomalous LSACP. The geopotential height anomalies (red and blue shading) at 500-hPa level are depicted by shaded contours. The anomalous zonal and meridional winds at 500$\mathrm{hPa}$ level are also illustrated by green vectors for the purpose of visualizing the location and range of cyclones and anticyclones. The corresponding node frequencies are displayed as percentages at the top of each panel. Generally, the LSACPs of adjacent nodes are more similar than those of distant nodes (Fig. 1). The nodes SOM-7 and SOM-6 have the highest frequency $(10.09 \%$ and $10 \%)$ with anticyclone as well as positive geopotential height anomalies over the coastal regions of eastern China and Japan. In node SOM-2, positive geopotential height anomalies cover the northeastern Asia, while negative geopotential height anomalies are over the western Pacific. Negative geopotential height anomalies associated with cyclones over the study area are identified in nodes SOM-3, SOM-4, SOM-5 and SOM- 9 within the study area. The node SOM-4 has the lowest frequency (6.39\%). Negative geopotential height anomalies dominate over the whole study region, while positive geopotential height anomalies are located at the Okhotsk Sea and the Ural Mountains, respectively.

The composites of Tmin anomalies for each SOM node in winter 

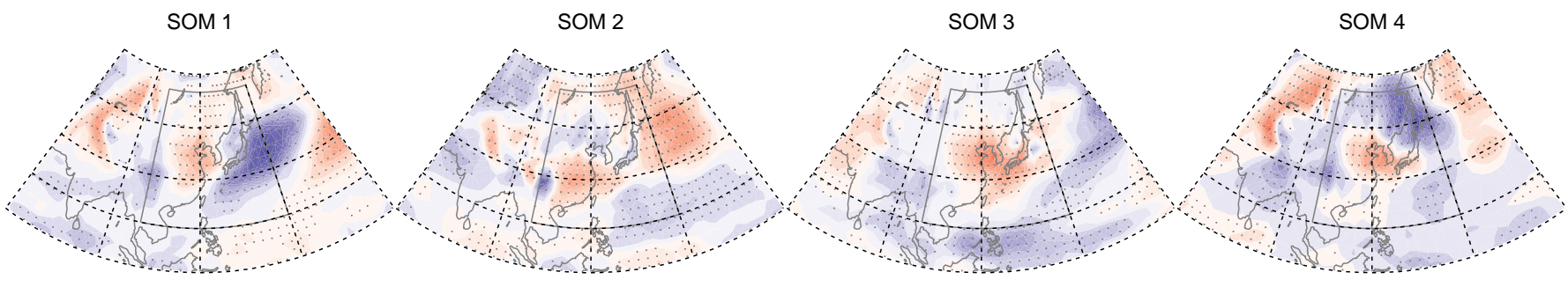

SOM 5

SOM 6

SOM 7

SOM 8
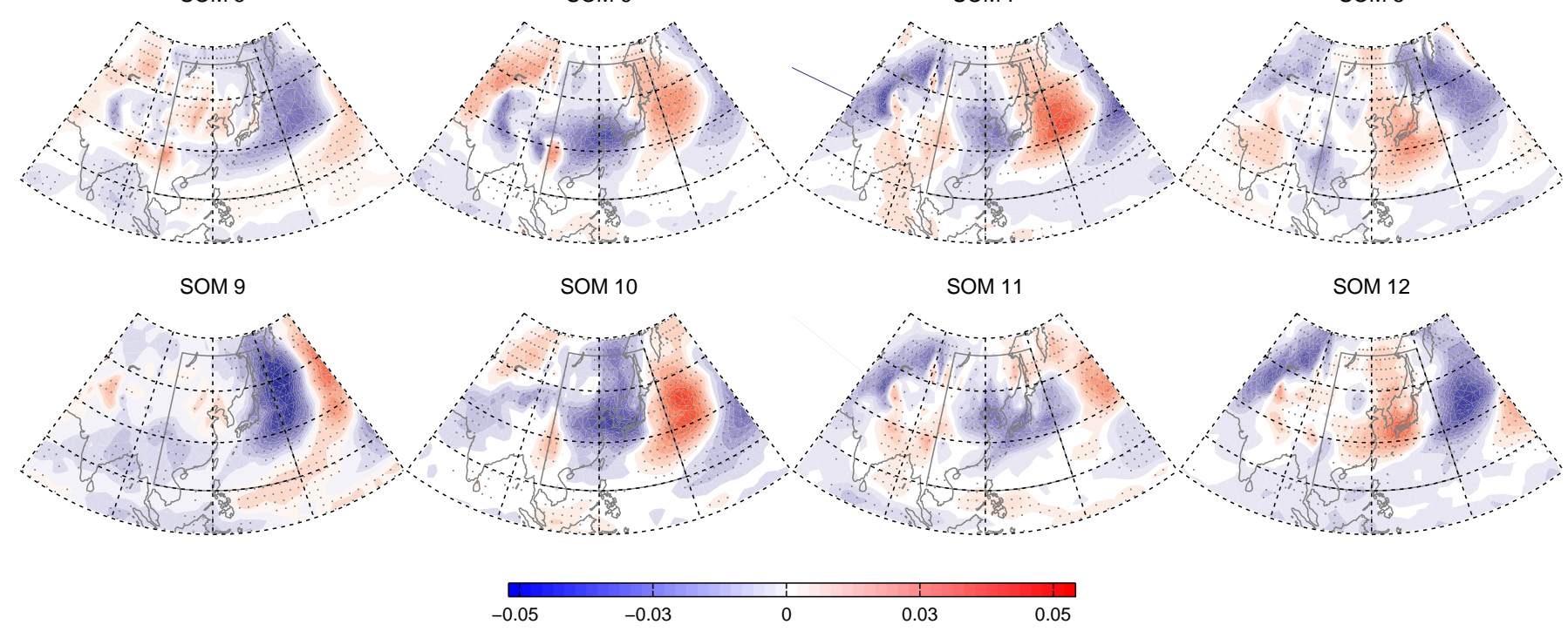

$-0.03$

0

0.03

0.05

Fig. 6. Composites of the normalized anomalies of vertical wind velocity at 500-hPa level in winter months (DJF).

months are shown in Fig. 2. Tmax composites are also computed and similar to the Tmin composites (not shown for winter months). The red (blue) shaded contours indicate the relatively high (low) normalized temperature anomalies. Generally, the negative temperature anomalies correspond to negative geopotential height anomalies and cyclones, while positive temperature anomalies correspond to positive geopotential height anomalies and anticyclones (Fig. 1). The consistence verifies the close relationship between LSACPs and temperature anomalies within the study area EAMR. The percentages of cold extreme occurring on days assigned to each node are shown in Fig. 3. Cold extremes are defined as the coldest $5 \%$ of the daily Tmin anomaly distribution. Only grid cells with statistically significant percentage at the $5 \%$ confidence level according to the Monte Carlo simulations are shaded in Fig. 3. From Fig. 3, we find that cold extremes are more associated with node SOM-1, SOM-3, SOM-4, SOM-5 and SOM-9 in winter months. Specifically, the cold extremes in SOM-3, SOM-4, and SOM-5 are associated with negative geopotential height anomalies and cyclones.

In Fig. 4, the precipitation anomalies corresponding to each SOM are presented using the green (orange) shaded contours. Also, the percentages of extreme precipitation event occurring on days assigned to each node are shown in Fig. 5. The spatial distribution of statistically significant extreme precipitation days is consistent with the precipitation anomalies shown in Fig. 4. In addition, the composites of vertical wind velocity anomalies at 500-hPa level corresponding to each SOM in winter months are shown in Fig. 6. Taking SOM-1 as an example, excessive precipitation mainly occurs in Japan and Korean Peninsula (Figs. 4 and 5) with a warm ascending air (Fig. 6) and wet southerlies (Fig. 1). Analogously, the excessive precipitation identified in SOM-4, SOM-6, SOM-7, SOM-8, SOM-9, SOM-10 and SOM-11 also could be explained jointly by the horizontal and vertical atmospheric motions.

\section{2) Summer months}

Fig. 7 shows the classified LSACPs generated by the SOM neural network for summer months. The grid size of the SOM neural network is also $3 \times 4$, and adjacent nodes share more commonalities than distant nodes. Node SOM-2 has the highest frequency (9.7\%) with both positive and negative geopotential height anomalies in the study area. The adjacent node SOM-1 has the lowest frequency (6.44\%) with a cyclone over northeastern Asia and centered at Lake Baikal. In node SOM-3, the cyclone moves east to the Okhotsk Sea and the anticyclone is centered at Lake Baikal. Node SOM-7 is characterized by positive geopotential height anomalies (anticyclones) over the northern part of the study area. In particular, there are three anticyclones cantered at the northeastern China, the Ural Mountains and the Bering Sea, respectively. SOM-6 resembles SOM-7 except for negative geopotential height anomalies over Bering Sea.

Fig. 8 shows the composites of Tmax anomalies for each SOM node in summer months. The temperature anomaly patterns are still consistent with the geopotential height anomaly patterns presented in Fig. 7. Similar to the cold extremes, the statistically significant percentages of warm extreme occurring on days assigned to each node are shown in Fig. 9, where warm extremes are defined as the warmest 5\% of the daily Tmax anomaly distribution. From Fig. 9, it can also be found that the associations between warm extremes and anticyclones are more intense at middle latitudes than low latitudes.

Composites of precipitation anomalies and percentages of extreme precipitation for each node in summer months are plotted in Figs. 10 


\section{Summer SOM Patterns}
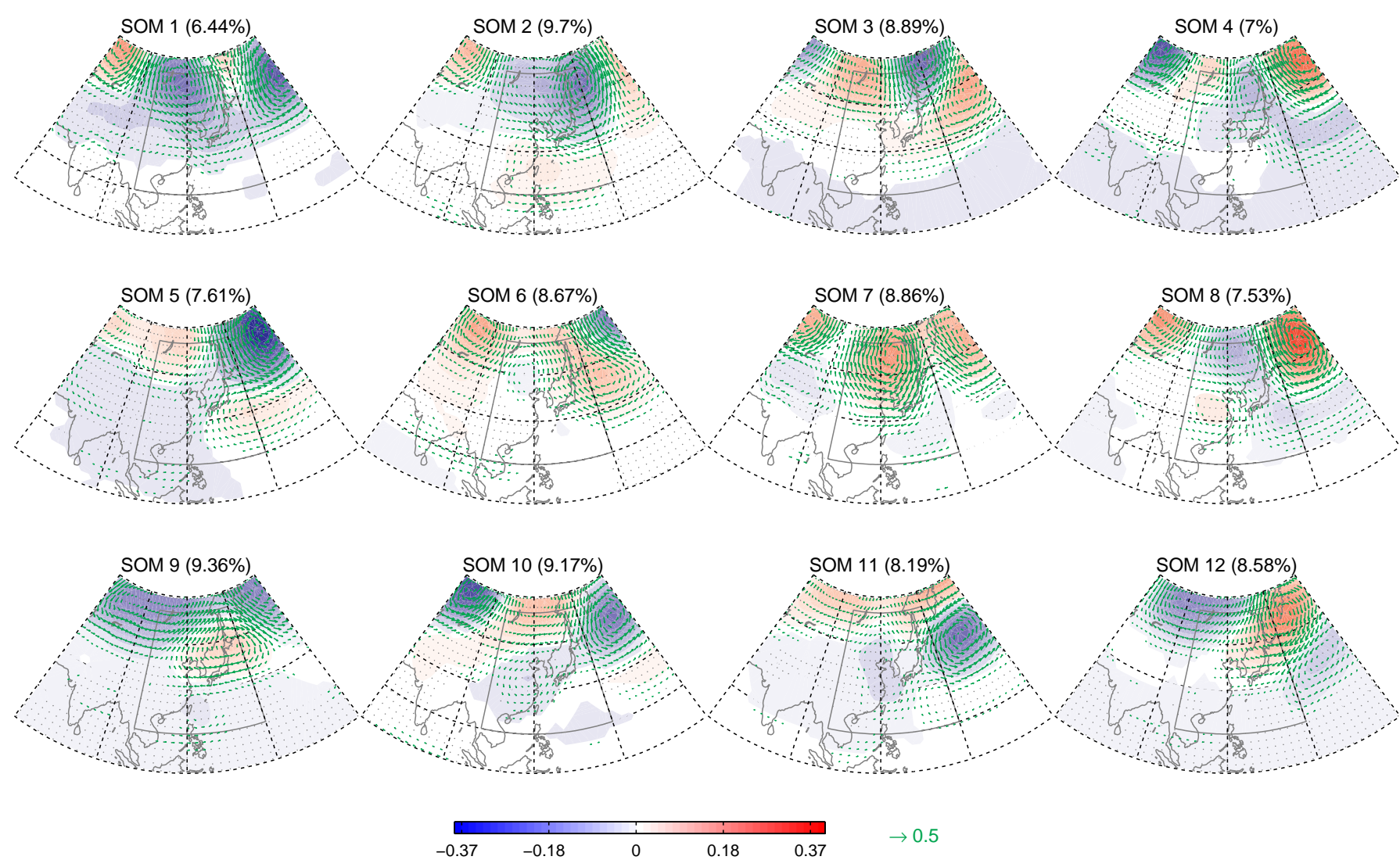

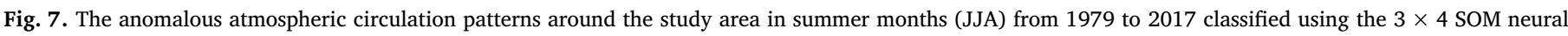

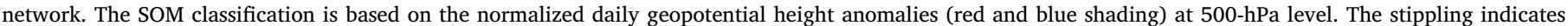

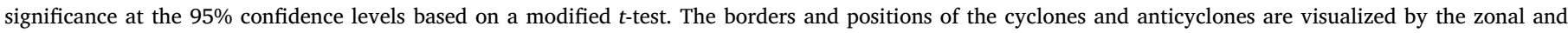

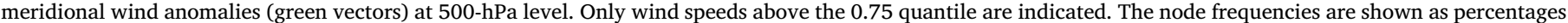
in the parentheses. (For interpretation of the references to colour in this figure legend, the reader is referred to the web version of this article.)

and 11, respectively. Unlike in winter months, statistically significant extreme precipitation events only account for a small part of precipitation anomalies in summer months (Figs. 10 and 11). Extreme precipitation events are usually sparsely distributed for each node. By comparing Figs. 7 and 10, we find that the locations of precipitation extremes and the locations of cyclones do not always coincide except for in node SOM-1. That means the horizontal atmospheric motions cannot effectively explain the extreme precipitation events in the study region. Fig. 12 shows the composites of vertical wind velocity anomalies in summer months. From Fig. 12, we see that the vertical atmospheric motions explain the excessive precipitation events in summer months more properly.

\subsection{Anomalous LSACPs and East Asian Monsoon}

The node frequencies on 150 winter/summer days with highest/ lowest EAWMI (WNPMI) values are shown in Fig. 13. In the strong EAWM phase (Fig. 13a), SOM-3 and SOM-4 are the two most frequent nodes and those do not occur in the weak EAWM phase. In the weak EAWM phase (Fig. 13b), nodes SOM-9 and SOM-11 account for $47 \%$ of all anomalous LSACPs. Moreover, the frequency differences for strong and weak phases of EAWM are shown in Fig. 13c. There are 7 nodes exhibit statistically significant difference at a $95 \%$ confidence level. Node SOM-3, SOM-4 and SOM-6 are more associated with strong EAWM. In particular, node- 3 and node- 4 are featured with cold extremes over the most part of the study area and negative precipitation anomalies in East China. In node SOM-6, the air temperature at the eastern coast of China, Korean Peninsula and Japan is not lower than the mean climatology, and central and eastern China is moister than normal condition due to the anticyclone centered at the study area EAMR. Nodes SOM-7, SOM-9, SOM-11 and SOM-12 are more associated with weak EAWM (Fig. 13c), and positive temperature anomalies are dominant in nodes SOM-7 and SOM-11. Since there are identified cyclones in node SOM-7 and SOM-12, cold extremes still occur within the study area (Figs. 2 and 3). Especially, nodes SOM-7, SOM-9 and SOM-11 exhibit the positive precipitation anomalies in Southeast China and Northeast Asia.

The node frequencies and frequency differences for strong and weak EASM phases are shown in Fig. 13(d-f). The associations between LSACPs and monsoon in summer months are not as tight as those in winter months. Only the differences of node frequency in 4 nodes are statistically significant at a 95\% confidence level. Nodes SOM-5 and SOM-9 are associated with strong summer EASM, while nodes SOM-1 and SOM-2 are associated with weak summer EASM. The node frequency difference in strong and weak EAWM and EASM phases will be discussed in detail in the next section.

\section{Discussions}

Atmospheric and oceanic circulations are the basic reasons for the 

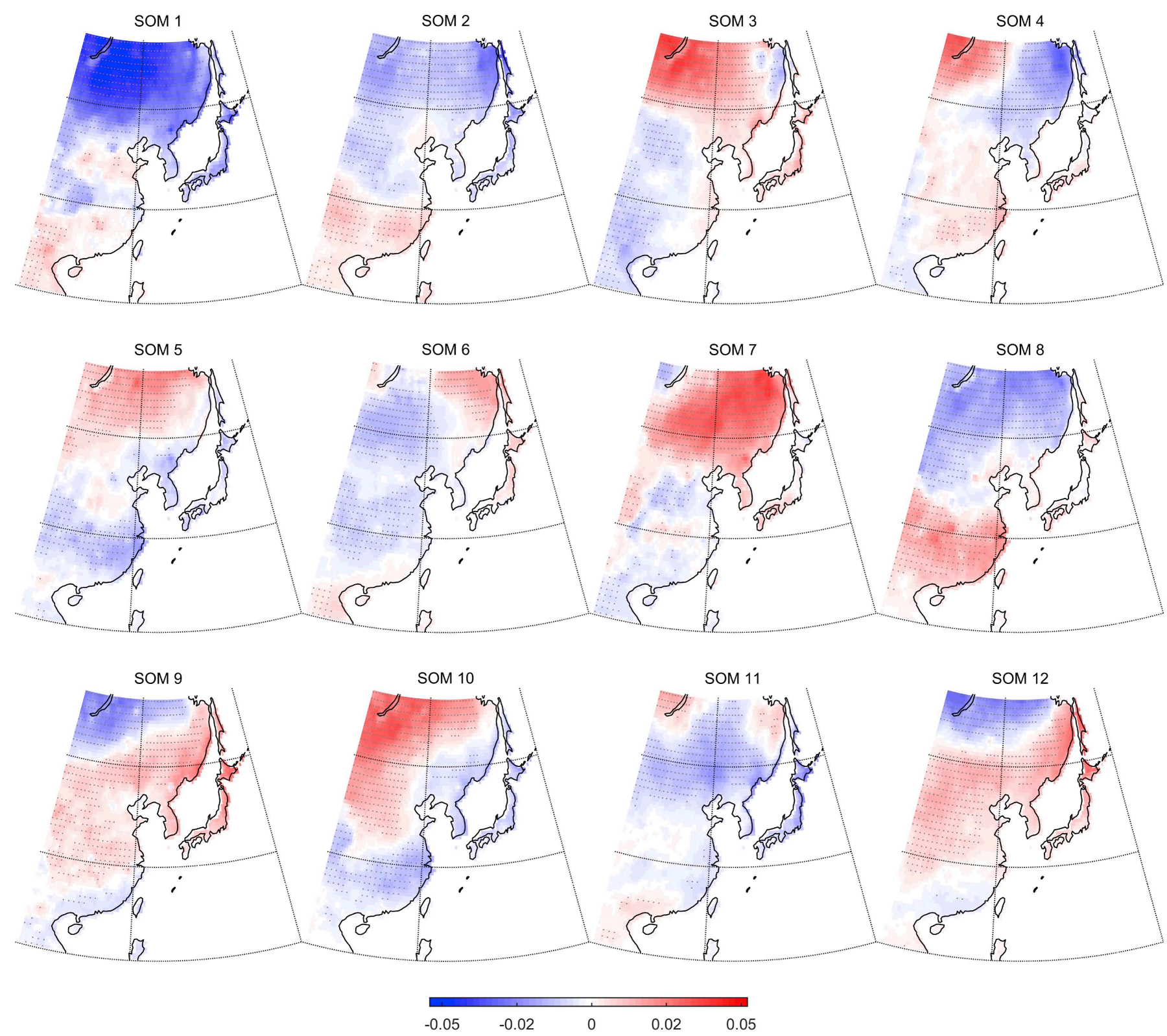

Fig. 8. Composites of daily maximum surface air temperature (Tmax) anomalies in summer months (JJA) from 1979 to 2017.

formation and evolution of climate extremes. The geopotential height anomalies at 500 -hPa level could effectively represent the middle-tropospheric circulations (You et al., 2011; Gao and Franzke, 2017; Loikith et al., 2017). However, Z500 was not usually chosen as the only input variable but as an element of a combination of a few of variables i.e. sea surface pressure (SLP), zonal and meridional winds (Loikith et al., 2017; Agel et al., 2017; Gao et al., 2019). In Horton et al. (2015), the SOM method with Z500 as the only input variable was also applied to identify different atmospheric circulations and quantified the relative contributions to changes in temperature extremes. In this study, we found that the anomalous LSACPs could be successfully identified and classified using the $3 \times 4$ SOM neural network with Z500 as the only input variable. The zonal and meridional wind anomalies were also presented in the composite maps just for the purpose of indicating the locations and ranges of cyclones and anticyclones. In addition, the vertical winds at 500-hPa level were composited based on the SOM classification to reveal the influence of vertical atmospheric motions on precipitation anomalies. We also performed the test using all the above atmospheric ingredients as the input variables of SOM, while the final conclusion was not qualitatively altered. The size of SOM neural network is typically user-defined and a moderate-sized map is preferred (Horton et al., 2015; Mioduszewski et al., 2016). In this study, the size of SOM neural network is $3 \times 4$ (Loikith et al., 2017). We also tested other grid sizes $(3 \times 3,4 \times 4,5 \times 5$, and $6 \times 6)$ and found that the asymmetric $3 \times 4$ SOM could capture and separate the important differences in LSACPs in winter and summer, respectively.

In winter months, a close relationship between LSACPs and temperature anomalies within the study area EAMR was verified in this study. Consistent relationship between LSACPs and temperature anomalies has been also found in China (Gao et al., 2019). Cold extremes were generally associated with negative geopotential height anomalies and cyclonic circulations. Horton et al. (2015) concluded 

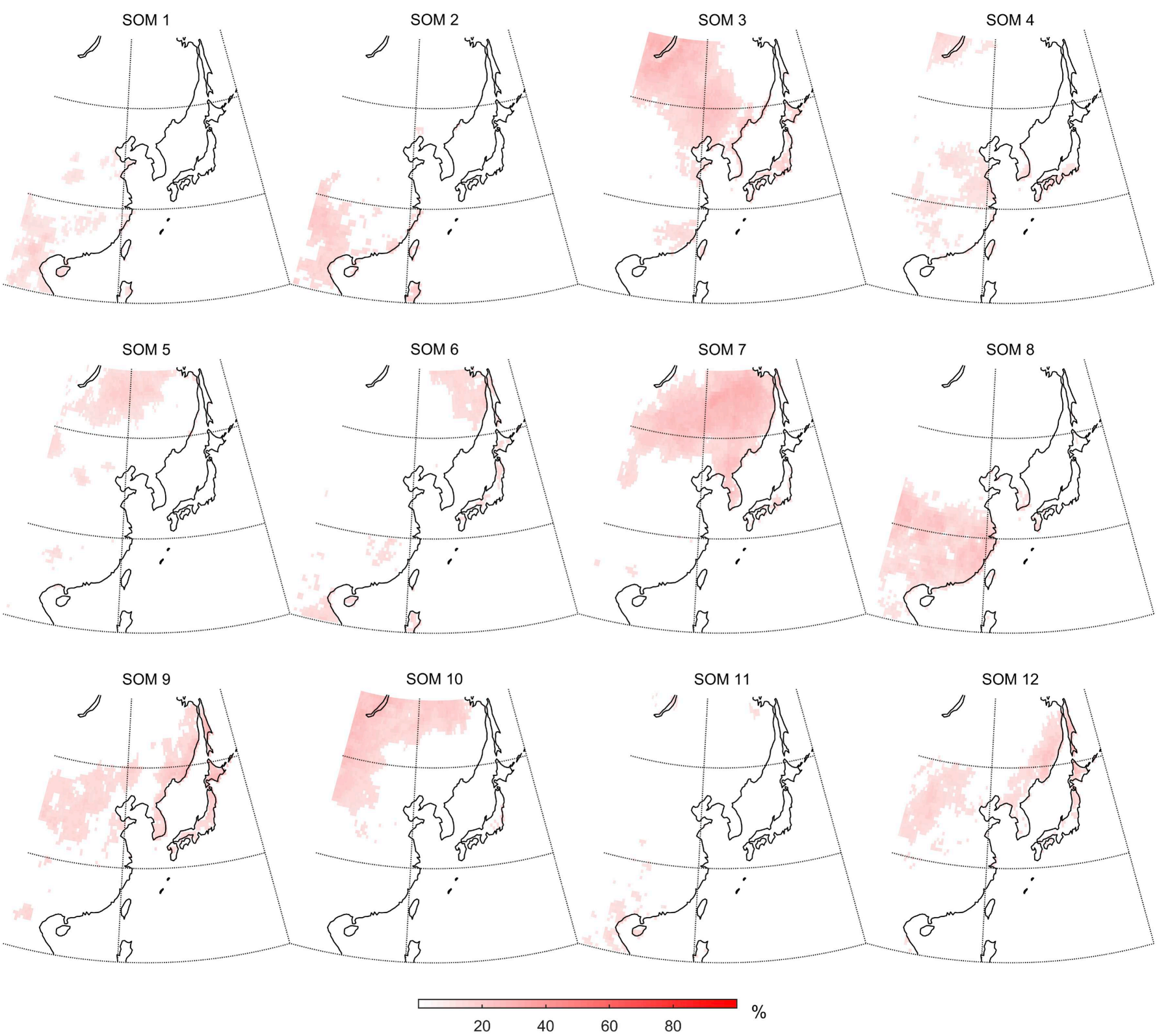

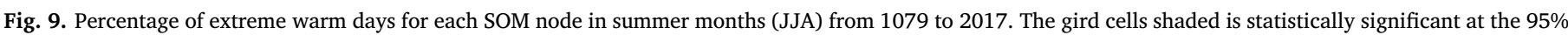
level based on the Monte Carlo simulations.

that the cold extremes in winter months over East Asia were due to the cyclonic circulation taking the cold air from Arctic into the study area EAMR. In our study, the cold anomalies and extremes were closely associated with the cyclonic circulation around the coast of EAMR and anticyclonic circulation over Eurasia at mid-high latitudes. The pattern implied that the East Asia Trough (EAT) extended southward. The northerly was predominant in the coast of EAMR located behind or in the trough (Wang et al., 2018). The strong meridional circulation resulted in cold temperature over the most areas of EAMR, and vice versa. In summer months, the temperature anomalies within the study area EAMR were also closely correlated to anomalous LSACPs. Specifically, summer warm extremes were usually associated with positive geopotential height anomalies and anticyclonic circulations (Wan et al., 2013). When the anticyclone controlled the northern continent of
EAMR, the Northeast China Cold Vortex (NCCV) was less active than normal condition. Besides, the anticyclone weakened the cold air from higher latitudes and promoted the warm air for lower latitudes into the controlled area. Hence, the warm extremes appeared over the northern EAMR. Especially, the positive geopotential height anomalies around $120 \mathrm{oE}$ at low latitudes implied that the Western Pacific Subtropical High (WPSH) was relatively strong and further westward and northward, which prevented the southward intrusion of cold air into South China thereby causing the warm extremes in this area (Zhang et al., 2017). Furthermore, the formation of anticyclonic circulation, raising a cascade of self-reinforcing, heat-accumulating physical process, was also favorable for extreme heat (Diffenbaugh et al., 2005; Miralles et al., 2014).

The vertical winds at $500-\mathrm{hPa}$ level representing the subsidence or 

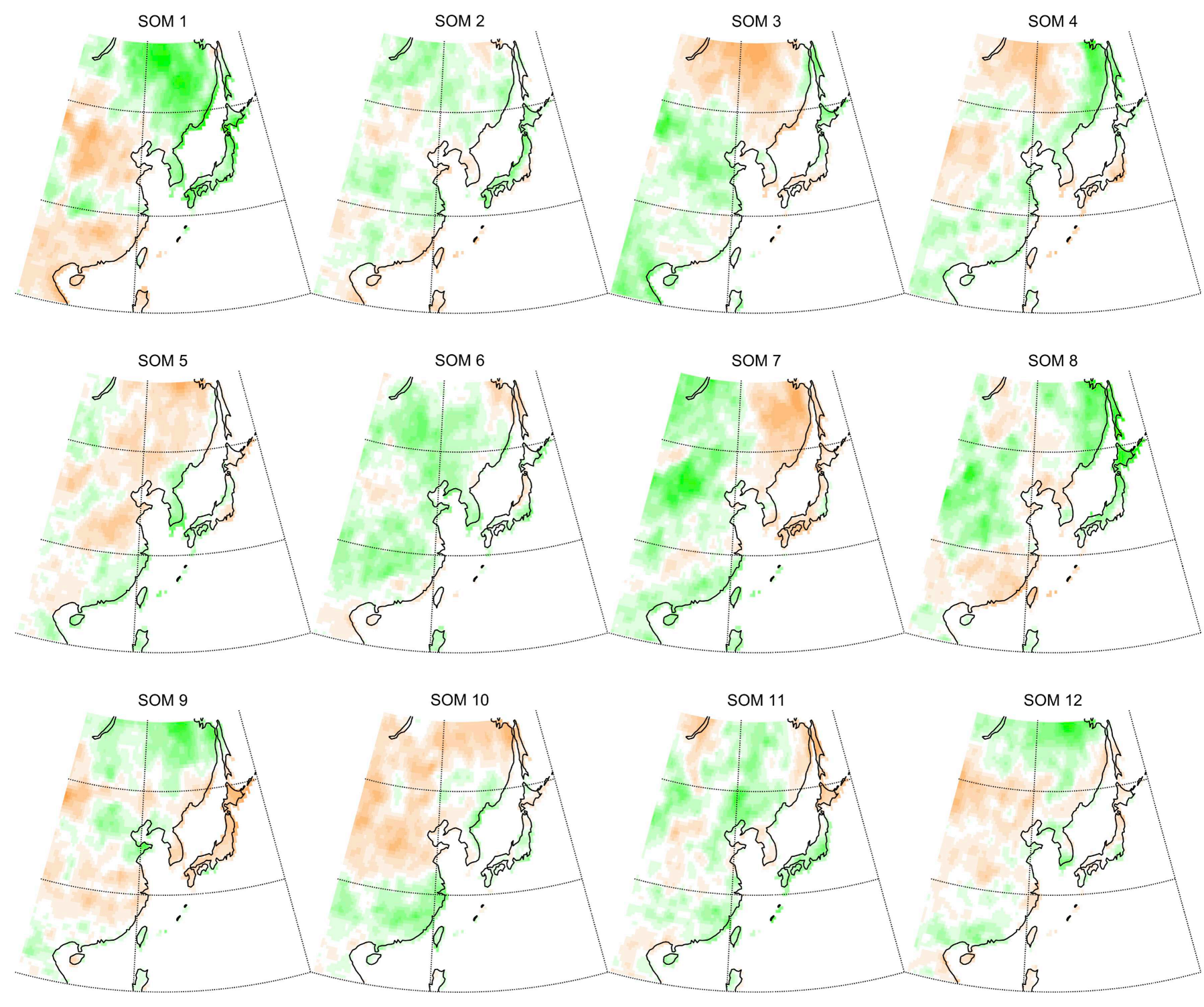

0

1

1.9

Fig. 10. Composites of daily precipitation anomalies in summer months (JJA). The definition of precipitation anomalies is shown in Data section.

ascendance of air mass assigned to each node were also composited to reveal the relationships between anomalous LSACPs and precipitation anomalies. There is no definite association between cyclone or anticyclone and air subsidence or ascendance (Fig. 1 vs Fig. 6, and Fig. 7 vs Fig. 12). In winter months, the widespread wet anomalies and extremes within the entire EAMR (Figs. 4 and 5) were triggered by the strong meridional circulation associated with ' - + -' wave train pattern of Z500 anomalies across the EAMR at mid-high latitudes. The pattern means the establishment of stable blocking in North Pacific, which suppressed the eastward movement of cyclonic circulation system and leaded the East Asia Trough (EAT) to become weaker than normal condition (Zhang et al., 2009; Zhao et al., 2016). Correspondingly, the southeasterly was developed and then enhanced humid air from the Pacific Ocean into the land. Meanwhile, the convection was relatively active over EAMR (Fig. 6). The upward atmospheric motion promoted the condensation of water vapor resulting in excessive precipitation.
Overall, the horizontal and vertical atmospheric motions jointly contributed to the precipitation extremes within the whole continent of EAMR. The precipitation extremes in the local area of study region were attributed to the zonal atmospheric circulation system. The zonal anticyclones/cyclones brought abundant moisture from ocean to land, in conjunction with the ascending atmospheric movement, playing together an important role on the precipitation extremes in local area. This result about extreme precipitation event was consistent with those in previous studies that manifest the precipitation extremes are mainly determined by the strong air convection and advection (Zhu et al., 2000). In summer months, the anomalous vertical winds solely explained the precipitation anomalies properly. Since the purpose of this study was to reveal the anomalous LSACPs and precipitation anomalies within EAMR, extreme precipitation events caused by tropical cyclones in summer months were not included in the current composite analysis. In future, the tropical cyclones should be considered independently 

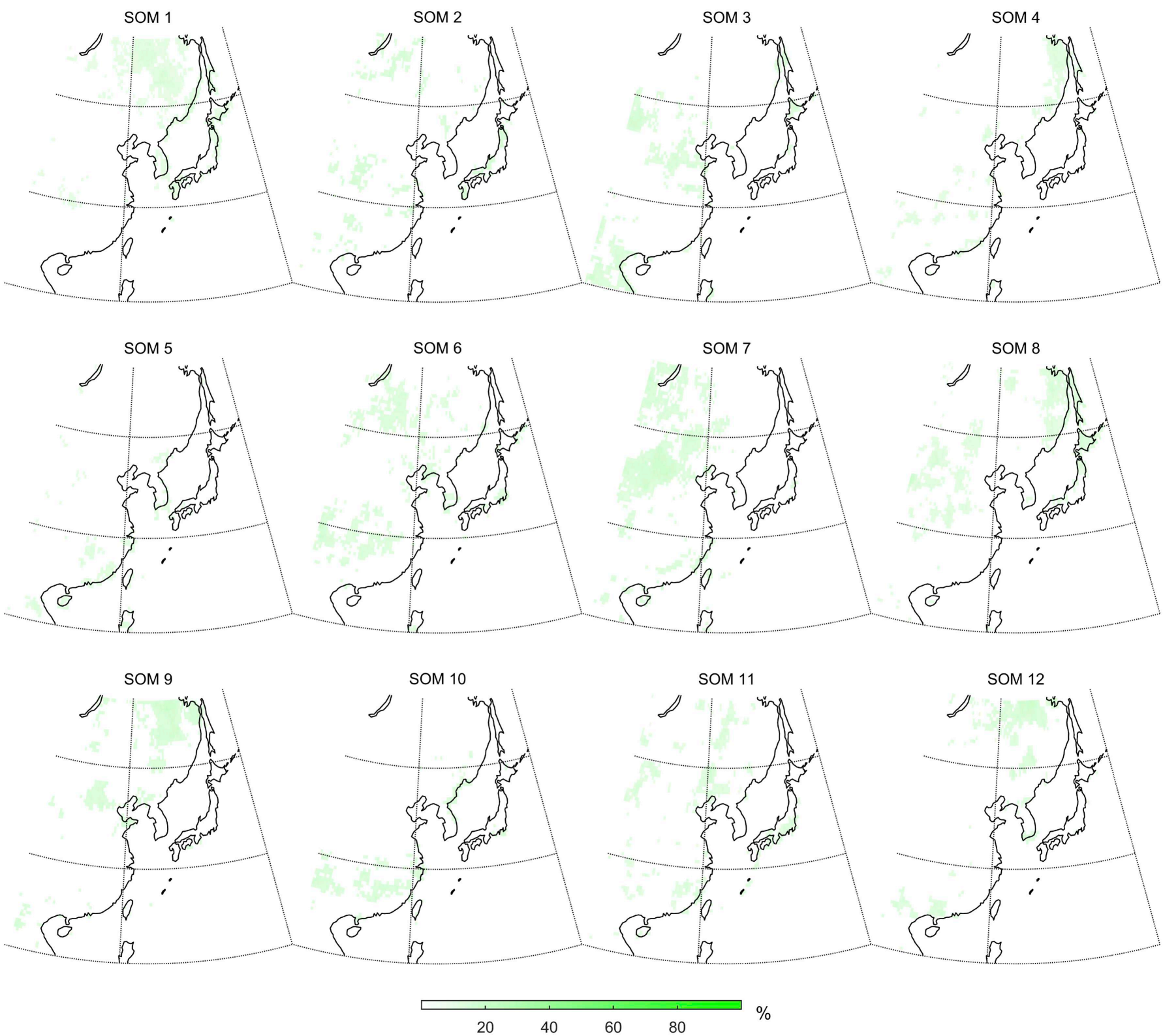

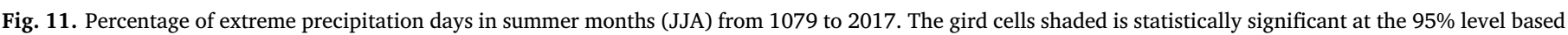
on the Monte Carlo simulations.

because of the tight association between tropical cyclones and heavy rains in East Asia (Lee et al., 2012).

East Asia is a typical monsoon region, where the monsoon circulation anomalies have serious impact on the local climatic variations (Gao, 2007). Chen (2002) found that the positive temperature anomalies usually were associated with the weak EAWM, while the negative temperature anomalies were associated with a strong EAWM over China. Wang and Feng (2011) proposed that the strong EAWM was characterized by a deepened mid-tropospheric trough in East Asia and the suppressed precipitation in Southeast China. The anomalous LSACPs and climate extremes under strong or weak EASM and EAWM conditions were also analyzed based on the SOM classification. In winter months, there were obvious differences in node frequency for strong and weak EAWM phases, and cold extremes and precipitation anomalies were associated with EAWM. Generally, the above findings were in accordance with those in previous relevant studies (Chen, 2002; Gao, 2007; Wang and Feng, 2011; Wang and Chen, 2014).

The relationships between EASM and LSACPs were a little complex in summer months. When EASM is strong (Fig. 13d), only SOM-5 and SOM-9, the leading two LSACPs, were statistically significant in frequency difference (Fig. 13f). EASM is a distinctive component of the Asian climate system; however, defining the intensity of the EASM has been extremely controversial (Wang et al., 2008). In this study, the WNPSM index was chosen as the measure for the EASM since it could well present the large-scale variability of Asia summer Monsoon (Wang et al., 2001). Nodes SOM-5 and SOM-9 were associated with strong summer EASM (Fig. 13), where anticyclones were identified around $30^{\circ} \mathrm{N}$ to $40^{\circ} \mathrm{N}$ (Fig. 7). The result was in line with that in Wang et al. (2001). The associations between nodes SOM-1 and SOM-2 with weak summer EASM were statistically significant at a $95 \%$ confidence level 

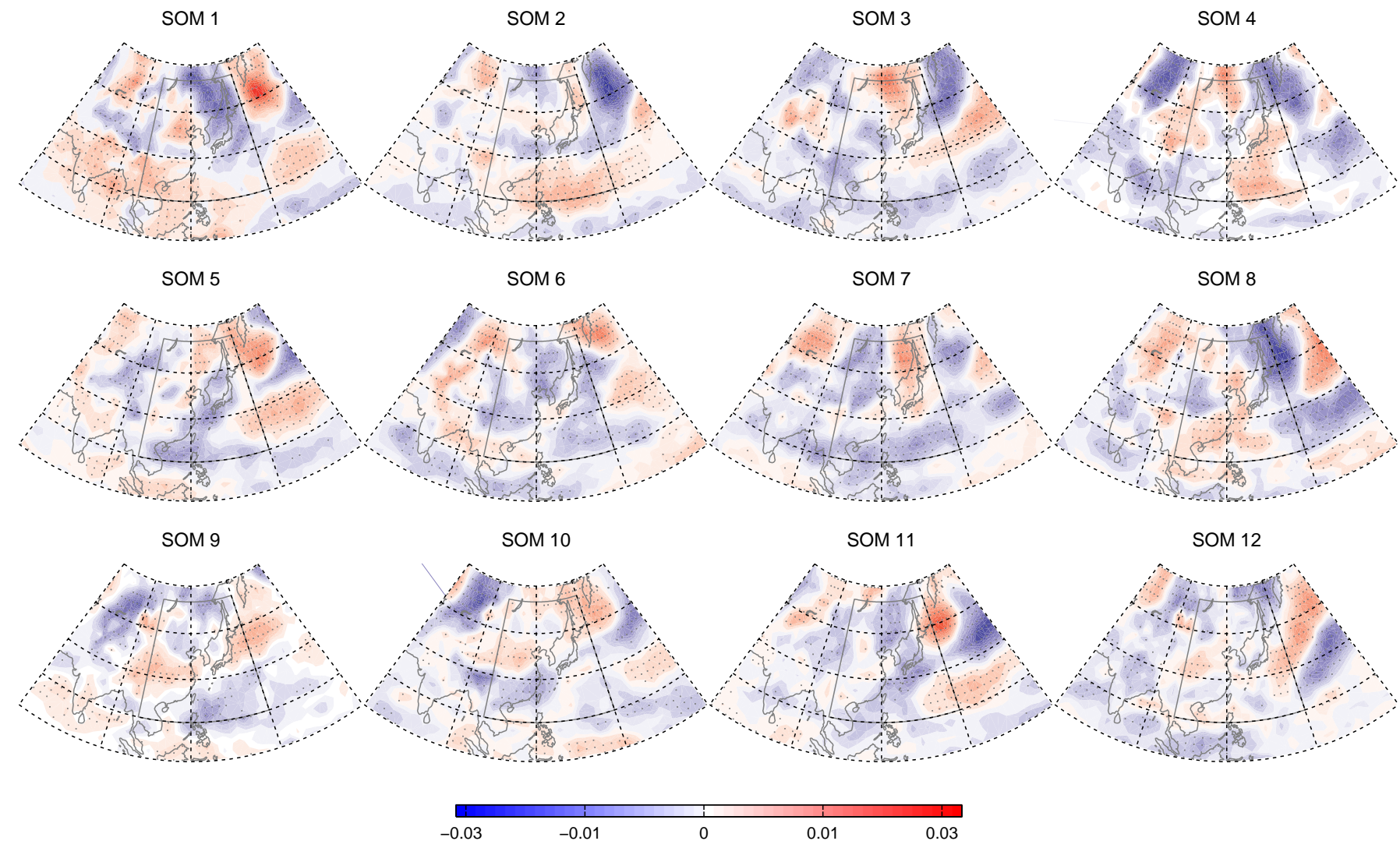

Fig. 12. Composites of the normalized anomalies of vertical wind velocity at 500-hPa level in summer months (JJA).

(Fig. 13). For node SOM-1 and SOM-2, cyclones were identified at the northern part of the study area (Fig. 7). Moreover, the enhanced rainfall along the mei-yu/baiu front was also observed for node SOM-1 and SOM-2 (Fig. 10). In general, the features of climate anomalies for different phases of EASM within the study area were in line with the conclusions documented in relevant studies (Shi and Zhu, 1996; Guo et al., 2004; Huang, 2004; Zhu et al., 2005; Wang et al., 2008).

Although the associations between LSACPs and climate extremes have been generally revealed by the SOM approach, the differences of LSACPs and climate anomalies in opposite phases of the EAWM/EASM were not fully discriminated (Fig. 13). Firstly, EAWM and EASM are the complicated and dynamic circulation systems. Wang et al. (2001) concluded that the EASM were interfered by the Indian summer monsoon (ISM) and western North Pacific summer monsoon (WNPSM). Fu et al. (2008) presented that the East Asian monsoon was also related tightly with Australian monsoon. Wang et al. (2008) found that the precipitation in northern China $\left(36^{\circ} \mathrm{N}-42^{\circ} \mathrm{N}\right)$ was often disturbed by the teleconnection with Indian monsoon or mid-latitude tropospheric activities, while precipitation anomalies in southern China $\left(20^{\circ} \mathrm{N}-26^{\circ} \mathrm{N}\right)$ were impacted by cyclonic circulations in the tropic. Wang and Chen (2014) proposed that the El Niño-Southern Oscillation, Eurasian pattern and North Pacific Oscillation have serious influence on the EAWM. In this study, the two monsoon indices, EAWMI and WNPMI, were chosen as the measure of East Asian Monsoon. Despite the two indices exhibit the excellent capacities for the description of the monsoon circulation, the simple index, determined by one element, is hard to represent completely the monsoon circulation systems over the entire East Asia (Gao, 2007; Wang et al., 2008). In future, multiple indices or a unified index will be adopted to determine the opposite strong/weak phases of East Asian Monsoon. Moreover, the climate anomalies, in particular, precipitation anomalies in East Asia show huge difference of spatial distribution and temporal evolution in longitude because of the immense territory and variation of solar radiation.

\section{Conclusions}

In this study, the SOM method has been applied to represent a continuum of anomalous LSACPs around East Asia $\left(0^{\circ}-60^{\circ} \mathrm{N}\right.$, $60^{\circ}-180^{\circ} \mathrm{E}$ ), and then linked the LSACPs with temperature and precipitation anomalies within the EAMR. The asymmetric $3 \times 4$ SOM neural network was constructed with the geopotential height anomalies at $500-\mathrm{hPa}$ level as the only input variable. With the created SOM neural network, 12 characteristic anomalous LSMPs (nodes) for the summer and winter seasons in the period 1979-2017 have been identified. In addition, the horizontal winds at 500-hPa level were also added into the composite maps of LSACPs to indicate the location and range of cyclones and anticyclones. Based on the SOM classification, the associations between LSACPs and climate anomalies (surface air temperature anomalies and precipitation anomalies) within the study area EAMR in winter and summer months were compactly visualized. The spatial distribution of anomalous geopotential height associated with cyclones/anticyclones was almost consistent with that of surface air temperature anomalies in both winter and summer months. The vertical wind velocity anomalies at $500-\mathrm{hPa}$ level were also composited to present the anomalous vertical atmospheric motions. The anomalous vertical atmospheric motions were not very consistent with the spatial distribution of temperature anomalies but consistent with the precipitation anomalies. Most precipitation extremes in winter months were due to the joint effect of the horizontal and vertical atmospheric motions, while strong air convection was prone to inducing extreme precipitation events in summer.

The classified anomalous LSACPs were also evaluated under strong or weak EASM and EAWM conditions. In winter months, the features of anomalous LSACPs for strong and weak phases of EAWM have been partly identified. Cold extremes were prone to associated with EAWM, whereas the relationship between the EAWM and precipitation was dependent on the position. In summer months, although the wet/dry 
(a) EAWMI+

\begin{tabular}{|c|c|c|c|}
\hline SOM 1 & SOM 2 & SOM 3 & SOM 4 \\
$8 \%$ & $2.67 \%$ & $24 \%$ & $25.33 \%$ \\
\hline SOM 5 & SOM 6 & SOM 7 & SOM 8 \\
$10.67 \%$ & $11.33 \%$ & $2.67 \%$ & $4.67 \%$ \\
\hline SOM 9 & SOM 10 & SOM 11 & SOM 12 \\
$0.67 \%$ & $10 \%$ & $0 \%$ & $0 \%$ \\
\hline
\end{tabular}

(b)EAWMI-

\begin{tabular}{|c|c|c|c|}
\hline SOM 1 & SOM 2 & SOM 3 & SOM 4 \\
$2.67 \%$ & $6 \%$ & $0 \%$ & $0 \%$ \\
\hline SOM 5 & SOM 6 & SOM 7 & SOM 8 \\
$4 \%$ & $0 \%$ & $14.67 \%$ & $5.33 \%$ \\
\hline SOM 9 & SOM 10 & SOM 11 & SOM 12 \\
$22 \%$ & $4 \%$ & $25.33 \%$ & $16 \%$ \\
\hline
\end{tabular}

(c) EAWMI+ vs. EAWMI-

\begin{tabular}{|c|c|c|c|}
\hline SOM 1 & SOM 2 & SOM 3 & SOM 4 \\
$5.33 \%$ & $-3.33 \%$ & $24 \%$ & $25.33 \%$ \\
\hline SOM 5 & SOM 6 & SOM 7 & SOM 8 \\
$6.67 \%$ & $11.33 \%$ & $-12 \%$ & $-0.67 \%$ \\
\hline SOM 9 & SOM 10 & SOM 11 & SOM 12 \\
\hline $\mathbf{- 2 1 . 3 3} \%$ & $6 \%$ & $-25.33 \%$ & $-16 \%$ \\
\hline
\end{tabular}

(d) WNPMI+

\begin{tabular}{|c|c|c|c|}
\hline SOM 1 & SOM 2 & SOM 3 & SOM 4 \\
$0 \%$ & $0.67 \%$ & $12 \%$ & $6.67 \%$ \\
\hline SOM 5 & SOM 6 & SOM 7 & SOM 8 \\
$12 \%$ & $6.67 \%$ & $10.67 \%$ & $4.67 \%$ \\
\hline SOM 9 & SOM 10 & SOM 11 & SOM 12 \\
\hline $18 \%$ & $14.67 \%$ & $4.67 \%$ & $9.33 \%$ \\
\hline
\end{tabular}

(e)WNPMI-

\begin{tabular}{|c|c|c|c|}
\hline SOM 1 & SOM 2 & SOM 3 & SOM 4 \\
$13.33 \%$ & $23.33 \%$ & $4.67 \%$ & $10 \%$ \\
\hline SOM 5 & SOM 6 & SOM 7 & SOM 8 \\
\hline $1.33 \%$ & $11.33 \%$ & $2 \%$ & $10 \%$ \\
\hline SOM 9 & SOM 10 & SOM 11 & SOM 12 \\
\hline $3.33 \%$ & $4.67 \%$ & $7.33 \%$ & $8.67 \%$ \\
\hline
\end{tabular}

(f) WNPMI+ vs. WNPMI-

\begin{tabular}{|c|c|c|c|}
\hline SOM 1 & SOM 2 & SOM 3 & SOM 4 \\
$\mathbf{- 1 3 . 3 3} \%$ & $-22.67 \%$ & $7.33 \%$ & $-3.33 \%$ \\
\hline SOM 5 & SOM 6 & SOM 7 & SOM 8 \\
\hline $10.67 \%$ & $-4.67 \%$ & $8.67 \%$ & $-5.33 \%$ \\
\hline SOM 9 & SOM 10 & SOM 11 & SOM 12 \\
\hline $14.67 \%$ & $10 \%$ & $-2.67 \%$ & $0.67 \%$ \\
\hline
\end{tabular}

Fig. 13. Node frequencies and frequency differences in weak and strong phases of East Asian Monsoon. Significant differences at a $95 \%$ confidence level are indicated in bold and italic font.

anomalies along the mei-yu/baiu were roughly responding to the weak/ strong EAWM, the differences of anomalous LSACPs, temperature and precipitation extremes within EAMR were not fully discriminated using the SOM method for strong and weak phases of EASM. The failure might due to the intrinsic complexity of the East Asia Monsoon system and the inherent limitations to the SOMs approach. It is necessary to adjust the SOM method to study the atmospheric circulations within the East Asia Monsoon system.

In conclusion, the SOM method was capable of classifying the anomalous LSACPs and identifying the association between anomalous LSACPs and extreme temperature and precipitation within EAMR. Linking anomalous LSACPs to climate anomalies can be potentially profitable to better understand the origin of climate extremes. In particular, this method could be used to assess the future changes in atmospheric circulations related to climate extremes. The detection of circulation pattern trends and the attribution of climate extreme changes within EAMR will be elucidated in future research.

\section{Declaration of Competing Interest}

The authors declare no conflict of interest.

\section{Acknowledgments}

This work was partly supported by the Youth Innovation Promotion Association of CAS, China (2016195), Key Research Project of Basic and Frontier Science of CAS, China (No. ZDBS-LY-7010), and National Natural Science Foundation of China (31570423).

\section{References}

Agel, L., Barlow, M., Feldstein, S.B., et al., 2017. Identification of large-scale meteorological patterns associated with extreme precipitation in the US northeast. Clim. Dyn. 50, 1819-1839.

Alexander, L.V., Zhang, X., Peterson, T.C., et al., 2006. Global observed changes in daily climate extremes of temperature and precipitation. J. Geophys. Res. 111, D05109.

Brown, T.J., Hall, B.L., 1999. The use of $t$ values in climatological composite analyses. J. Clim. 12, 2941-2945.

Brown, S.J., Caesar, J., Ferro, C.A.T., 2008. Global changes in extreme daily temperature since 1950. J. Geophys. Res. Atmos. 113, D05115.

Cassano, J.J., Uotila, P., Lynch, A., 2006. Changes in synoptic weather patterns in the polar regions in the twentieth and twenty-first centuries, part 1: Arctic. Int. J. Climatol. 26, 1027-1049.

Cassano, J.J., Uotila, P., Lynch, A.H., et al., 2007. Predicted changes in synoptic forcing of net precipitation in large Arctic river basins during the 21st century. J. Geophys. Res. 112, G04S49.

Chen, W., 2002. Impacts of El Nino and La Nina on the cycle of the East Asian winter and 
summer monsoon. Chin. J. Atmos. Sci. 26 (5), 595-610 1006-9895.

Dee, D.P., Uppala, S.M., Simmons, A.J., et al., 2011. The ERA-Interim Reanalysis: configuration and performance of the data assimilation system. Q. J. R. Meteorol. Soc 137, 553-597.

Diffenbaugh, N.S., Pal, J.S., Trapp, R.J., et al., 2005. Fine-scale processes regulate the response of extreme events to global climate change. Proc. Natl. Acad. Sci. U. S. A $102,15774-15778$.

Ding, Y., Chan, J.C.L., 2005. The East Asian summer monsoon: an overview. Meteorog. Atmos. Phys. 89, 117-142.

Ford, T.W., Schoof, J.T., 2017. Characterizing extreme and oppressive heat waves in Illinois. J. Geophys. Res. Atmos. 122, 682-698.

Fu, C., Jiang, Z., Guan, Z., et al., 2008. Regional Climate Studies of China. Springer, Berlin.

Gao, H., 2007. Comparison of four East Asian winter monsoon indices. Acta Meteorol.Sinica. 65, 272-279. 0577-6619.

Gao, M., Franzke, C.L.E., 2017. Quantile regression-based spatiotemporal analysis of extreme temperature change in China. J. Clim. 30, 9897-9914.

Gao, M., Mo, D., Wu, X., 2016. Nonstationary modeling of extreme precipitation in China. Atmos. Res. 182, 1-9.

Gao, M., Yang, Y., Shi, H., Gao, Z., 2019. SOM-based synoptic analysis of atmospheric circulation patterns and temperature anomalies in China. Atmos. Res. 220, 46-56.

Grotjahn, R., Lee, Y.-Y., 2016. On climate model simulations of the large-scale meteorology associated with California heat waves. J. Geophys. Res. Atmos. 121, 18-32.

Guo, Q., Cai, J., Shao, X., et al., 2004. Studies on the variations of East-Asian summer monsoon during A.D. 1873-2000. Chin. J. Atmos. Sci. 28 (206-215), 1006-9895.

Hart, M., De Dear, R., Hyde, R., 2006. A synoptic climatology of tropospheric ozone episodes in Sydney, Australia. Int. J. Climatol. 26, 1635-1649.

Haylock, M.R., Peterson, T.C., Alves, L.M., et al., 2006. Trends in total and extreme South American rainfall in 1960-2000 and links with sea surface temperature. J. Clim. 19, 1490-1512.

Hewitson, B.C., Crane, R.G., 2002. Self-organizing maps: applications to synoptic climatology. Clim. Res. 22, 13-26.

Higgins, R.W., Yao, Y., Wang, X.L., 1997. Influence of the North American monsoon system on the U.S. summer precipitation regime. J. Clim. 10, 2600-2622.

Horton, D.E., Johnson, N.C., Singh, D., et al., 2015. Contribution of changes in atmospheric circulation patterns to extreme temperature trends. Nature. 522, 465-469.

Huang, G., 2004. An index measuring the interannual variation of the East Asian summer monsoon - the EAP index. Adv. Atmos. Sci. 21, 41-52.

Huang, R., Zhou, L., Chen, W., 2003. The progresses of recent studies on the variabilities of the East Asian monsoon and their causes. Adv. Atmos. Sci. 20, 55-69.

IPCC, 2007. Climate Change 2007: The Physical Science Basis. Cambridge University Press, pp. 996.

Katz, R.W., Brown, B.G., 1992. Extreme events in a changing climate: Variability is more important than averages. Clim. Chang. 21, 289-302.

Klein Tank, A.M.G., Peterson, T.C., Quadir, D.A., et al., 2006. Changes in daily temperature and precipitation extremes in central and South Asia. J. Geophys. Res. Atmos. 111, D16105.

Kohonen, T., 1995. Self-organizing Maps. In: Springer Series in Information Sciences. vol. 30 Springer, Berlin.

Lau, N.C., Nath, M.J., 2014. Model simulation and projection of European heat waves in present-day and future climates. J. Clim. 27, 3713-3730.

Lee, M., Ho, C., Kim, J., Song, H., 2012. Low-frequency variability of tropical cycloneinduced heavy rainfall over East Asia associated with tropical and North Pacific Sea surface temperatures. J. Geophys. Res. 117, D12101.

Li, Z., He, Y., Wang, P., et al., 2012. Changes of daily climate extremes in southwestern China during 1961-2008. Glob. Planet. Chang. 80-81, 255-272.

Liu, Y., Weiberg, R.H., 2011. A review of self-organizing map applications in meteorology and oceanography. In: Mwasiagi, J.I. (Ed.), Self-Organizing Maps - Applications And Novel Algorithm Design. IntechOpen.

Loikith, P.C., Lintner, B.R., Sweeney, A., 2017. Characterizing large-scale meteorological patterns and associated temperature and precipitation extremes over the northwestern United States using self-organizing maps. J. Clim. 30, 2829-2847.

Mioduszewski, J.R., Rennermalm, A.K., Hammann, A., et al., 2016. Atmospheric drivers of Greenland surface melt revealed by self-organizing maps. J. Geophys. Res. Atmos. 121, 5095-5114.
Miralles, D.G., Teuling, A.J., van Heerwaarden, C.C., et al., 2014. Mega-heatwave temperatures due to combined soil desiccation and atmospheric heat accumulation. Nat. Geosci. 7, 345-349.

Ohba, M., Kadokura, S., Yoshida, Y., et al., 2015. Anomalous weather patterns in relation to heavy precipitation events in Japan during the Baiu season. J. Hydrometeorol. 16, 688-700.

Peterson, T.C., Taylor, M.A., Demeritte, R., et al., 2002. Recent changes in climate extremes in the Caribbean region. J. Geophys. Res. Atmos. 107 (ACL 16-1-ACL 16-9).

Riddle, E.E., Stoner, M.B., Johnson, N.C., et al., 2013. The impact of the MJO on clusters of wintertime circulation anomalies over the North American region. Clim. Dyn. 40, 1749-1766.

Robeson, S.M., 2002. Relationships between mean and standard deviation of air temperature: implications for global warming. Clim. Res. 22, 205-213.

Sheridan, S.C., Lee, C.C., 2012. The self-organizing map in synoptic climatological research. Prog. Phys. Geogr. 35 (1), 109-119.

Shi, N., Zhu, Q., 1996. An abrupt change in the intensity of the East Asian summer monsoon index and its relationship with temperature and precipitation over East China. Int. J. Climatol. 16, 757-764.

Trenberth, K.E., Stepaniak, D.P., Caron, J.M., 2000. The global monsoon as seen through the divergent atmospheric circulation. J. Climate. 13, 3969-3993.

Tolika, K., Maheras, P., Vafiadis, M., et al., 2007. Simulation of seasonal precipitation and raindays over Greece: a statistical downscaling technique based on artificial neural networks (ANNs). Int. J. Climatol. 27, 861-881.

Wan, H., Zhong, Z., Yang, X., et al., 2013. Impact of city belt in Yangtze River Delta in China on a precipitation process in summer: a case study. Atmos. Res. 125, 63-75.

Wang, L., Chen, W., 2014. An intensity index for the East Asian winter monsoon. J. Clim. 27, 2361-2374.

Wang, L., Feng, J., 2011. Two major modes of the wintertime precipitation over China. Chin. J. Atmos. Sci. 35, 1006-9895 1105-1116.

Wang, B., Ho, L., 2002. Rainy season of the Asian-Pacific summer monsoon. J. Clim. 15, 386-398.

Wang, B., Wu, R., Lau, K.-M., 2001. Interannual variability of the Asian summer monsoon: contrasts between the Indian and the western North Pacific-east Asian monsoons. J. Clim. 14, 4073-4090.

Wang, B., Wu, Z., Li, J., et al., 2008. How to measure the strength of the East Asian summer monsoon. J. Clim. 21, 4449-4463.

Wang, J., Qu, W., Li, C., et al., 2018. Spatial distribution of wintertime air pollution in major cities over eastern China: relationship with the evolution of trough, ridge and synoptic system over East Asia. Atmos. Res. 212, 186-201.

Wen, X., Fang, G., Qi, H., et al., 2015. Changes of temperature and precipitation extremes in China: past and future. Theor. Appl. Climatol. 126, 369-383.

Wu, B., Zhou, T., Li, T., 2009. Seasonally evolving dominant interannual variability modes of East Asian climate. J. Clim. 22, 2992-3005.

Yarnal, B., 1993. Synoptic Climatology in Environmental Analysis. Belhaven Press, London.

You, Q.L., Kang, S.C., Aguilar, E., et al., 2011. Changes in daily climate extremes in China and their connection to the large scale atmospheric circulation during 1961-2003. Clim. Dyn. 36, 2399-2417.

Zhai, P., Sun, A., Ren, F., et al., 1999. In: Karl, T.R., Nicholls, N., Ghazi, A. (Eds.), Weather And Climate Extremes: Changes, Variations And A Perspective From The Insurance Industry. Springer, Netherlands, Dordrecht, pp. 203-218 Changes of climate extremes in China.

Zhang, Z., Gong, D., Hu, M., et al., 2009. Anomalous winter temperature and precipitation events in southern China. J. Geogr. Sci. 19, 471-488.

Zhang, L., Chen, L., Zhou, Y., et al., 2017. Dominant modes of summer temperature over China and its associated circulation anomalies. Meteorol. Monthly. 43, 1393-1401 1000-0526.

Zhao, C.-Y., Fang, Y.-H., Luo, Y., et al., 2016. Interdecadal component variation characteristics in heavy winter snow intensity in North-Eastern China and its response to sea surface temperatures. Atmos. Res. 180, 165-177.

Zhu, Q., Lin, J., Shou, S., Tang, D., 2000. Principles and Methods of Meteorology. China Meteorological Press, Beijing.

Zhu, C., Lee, W.S., Kang, H., et al., 2005. A proper monsoon index for seasonal and interannual variations of the East Asian monsoon. Geophys. Res. Lett. 32, L02811. 